\title{
Los murales de Arte para todos en Sevilla. Dialéctica entre la conservación y el olvido
}

Pau Aleixandre Hernandis | Graduada en Conservación y Restauración de Bienes Culturales

URL de la contribución <www.iaph.es/revistaph/index.php/revistaph/article/view/4904>

En esta última década estamos siendo testigos del nacimiento de un nuevo movimiento en el arte urbano. El muralismo contemporáneo o neomuralismo (Schacter 2016), para algunos considerado como una escisión con la subcultura del graffiti nacida en los años 80 (Sánchez Pons 2016), se está asentando tanto en las grandes urbes como en las localidades más diseminadas. La creación de estas obras se contempla dentro del marco legal, hecho que los hace más susceptibles de ser separados del concepto de arte urbano como acto vandálico heredado durante décadas que, afortunadamente, ya se está empezando a superar. Los artífices de estos murales son artistas formados y de gran reconocimiento, algunos con una amplia carrera a medio camino entre lo legal y lo ilegal, la calle y la galería. Son parte activa del arte contemporáneo, siendo reclamados por su alto nivel en todas las ciudades del mundo que abracen este movimiento.

España ha sido objetivo de múltiples festivales y proyectos de arte urbano comisionados por la administración pública e instituciones, tanto nacionales como internacionales. Es el caso del proyecto Arte para todos, acontecido en Sevilla en el año 2010 con el patrocinio de la ONU, cuyo objetivo era trasladar a la población los valores contemplados en los Objetivos del Milenio (García 2010; Naciones Unidas 2010). Desde entonces, los barrios A y B de San Pablo han estadosalpicados de murales reivindicativos, cuyos mensajes de lucha social, igualdad e identidad conectaron rápidamente con los habitantes del barrio.

Las obras de este evento fueron donadas a la ciudad de Sevilla (Estévez 2010), transacción que convertiría a la administración local en la principal responsable de la gestión y conservación de los murales. La fuerte colaboración y diálogo entre los artistas y los ciudadanos

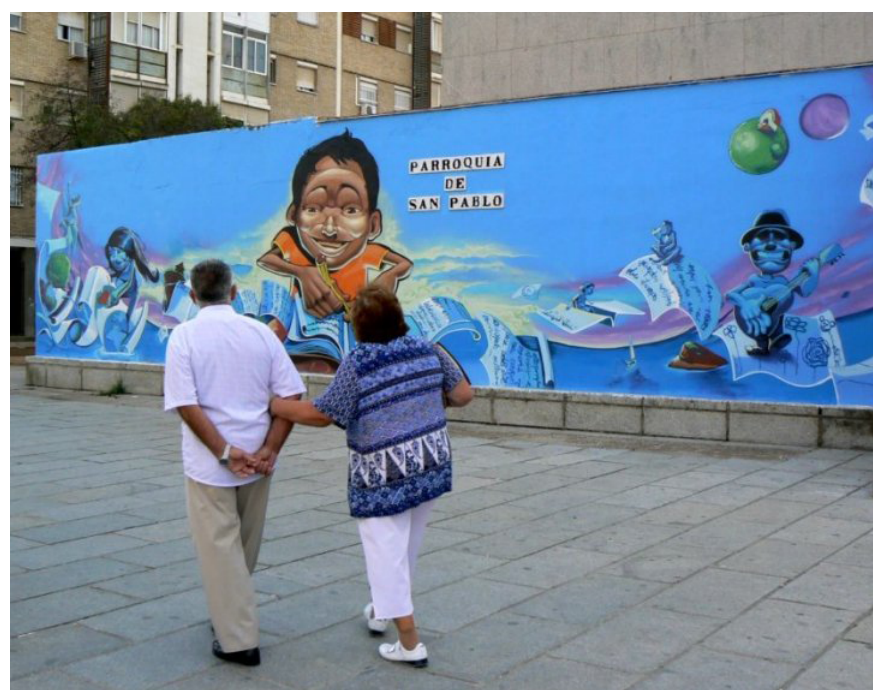

Murales del proyecto Arte para todos | fotos Martín Javier Fernández Muñoz, autor de todas las imágenes que ilustran esta contribución

generó de manera casi automática un vínculo identitario, sintiendo esas obras como propias y formando ya parte de su patrimonio, en un barrio donde el asfalto y el cemento habían sido los protagonistas hasta entonces. Ya desde el planteamiento inicial de este proyecto, uno de los principales objetivos era la conservación de los murales a largo plazo. Para ello se prepararon los soportes y se aplicó una capa final de protección (Laboratorio Q 2021).

A lo largo de su década de existencia se han llevado a cabo distintas actividades de dinamización relacionadas con el arte urbano que intentaban establecer un vínculo entre el público joven y adolescente y estas obras, como el festival Experimento San Pablo, que tuvo dos ediciones. No obstante, desde la última, realizada el año 2014 (Piñero 2014) no ha tenido lugar evento alguno, no se han movilizado las instituciones, empezando a desarro- 
llarse un fenómeno de fosilización de los murales de San Pablo. Queda patente pues, pese a esta voluntad inicial citada en el párrafo anterior, una ausencia de un plan de conservación preventiva más que notable.

Analizando la situación de las obras de los barrios A y $B$ de San Pablo, lo primero que se detecta es un déficit en la gestión administrativa de estos bienes. La principal amenaza de estas obras es la desvinculación de los habitantes del barrio con su significado. Sin un esfuerzo por parte de las instituciones responsables por mantener este patrimonio dinamizado e interpretado, la conciencia del público se desvanece. Las obras pierden su valor y son víctimas de uno de los mayores enemigos del patrimonio: el abandono y el olvido. Como consecuencia ya se empiezan a detectar graves daños en algunas de los murales, así como intervenciones no profesionales sobre algunos de ellos que presentan daños estructurales, pero todavía hay una oportunidad de actuar bien y a tiempo.

Recientemente se está a empezando a plantear la aplicación de planes de conservación preventiva en mura- les contemporáneos, no sin dar paso a amplios debates. Desde nuestra reflexión, creemos que la conservación preventiva del arte urbano debería llegar hasta los límites en los que se establecen las obras ilegales o alegales, acotando la actuación sobre aquellas obras comisionadas como es el caso que nos ocupa. La protección de estas obras no sería un caso aislado, pues ya contamos con grandes proyectos de conservación preventiva, como el de las obras del festival de arte urbano Vigo Ciudad de color (Fernández Arcos 2019), que contribuyen en la justificación de la necesidad cada vez más palpable de elaborar estos planes ante el arte urbano comisionado. Mediante ellos podemos conseguir una mayor implicación por parte de las administraciones responsables de estas obras en cuanto a su gestión y conservación, sin por ello olvidar el indispensable papel que cumplen otros agentes como los habitantes del barrio, artistas, instituciones, etc., para mantener viva la significancia de este patrimonio.

Para terminar, queremos poner un foco sobre otras herramientas que, en simbiosis con los planes de con-
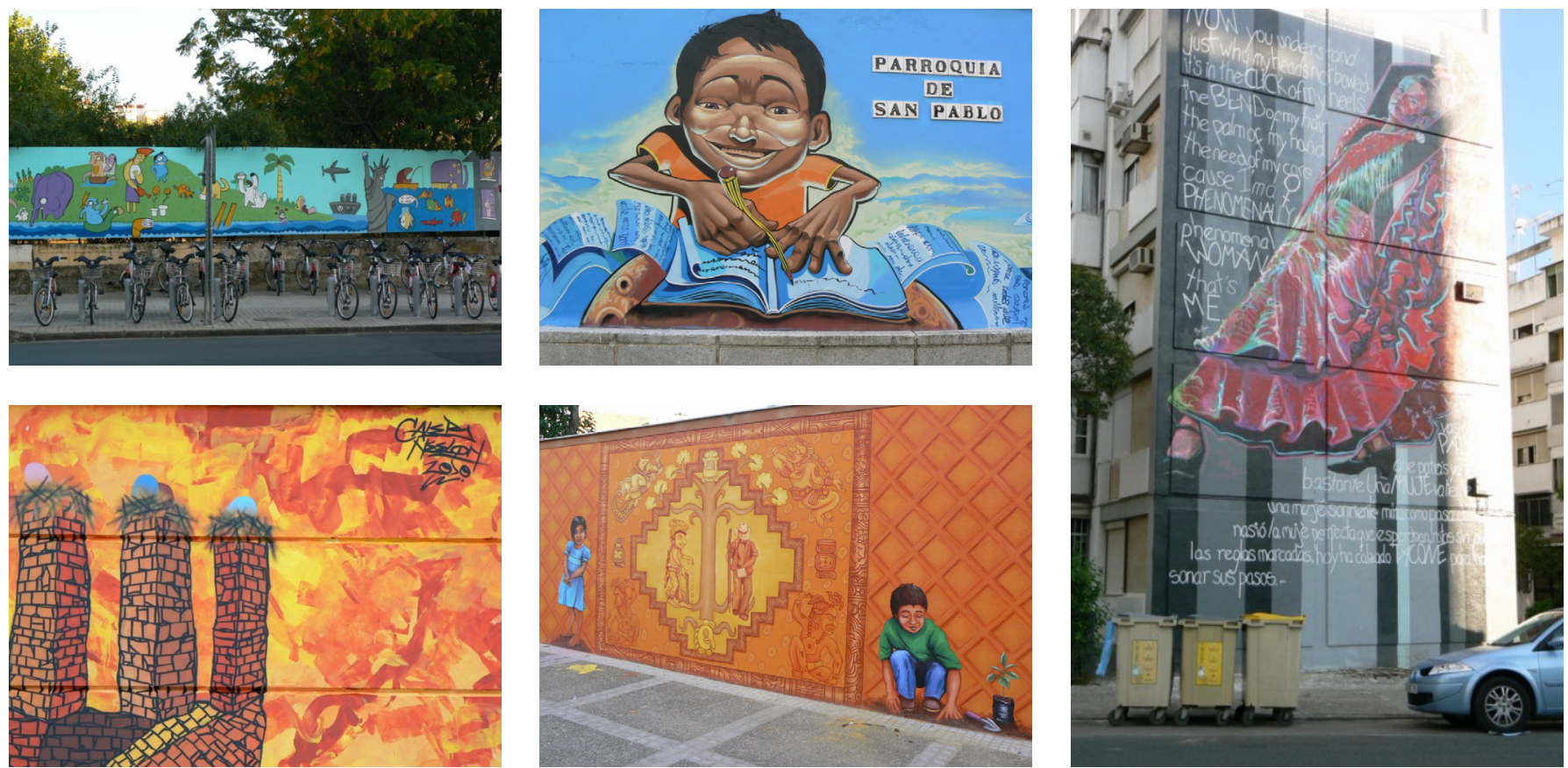

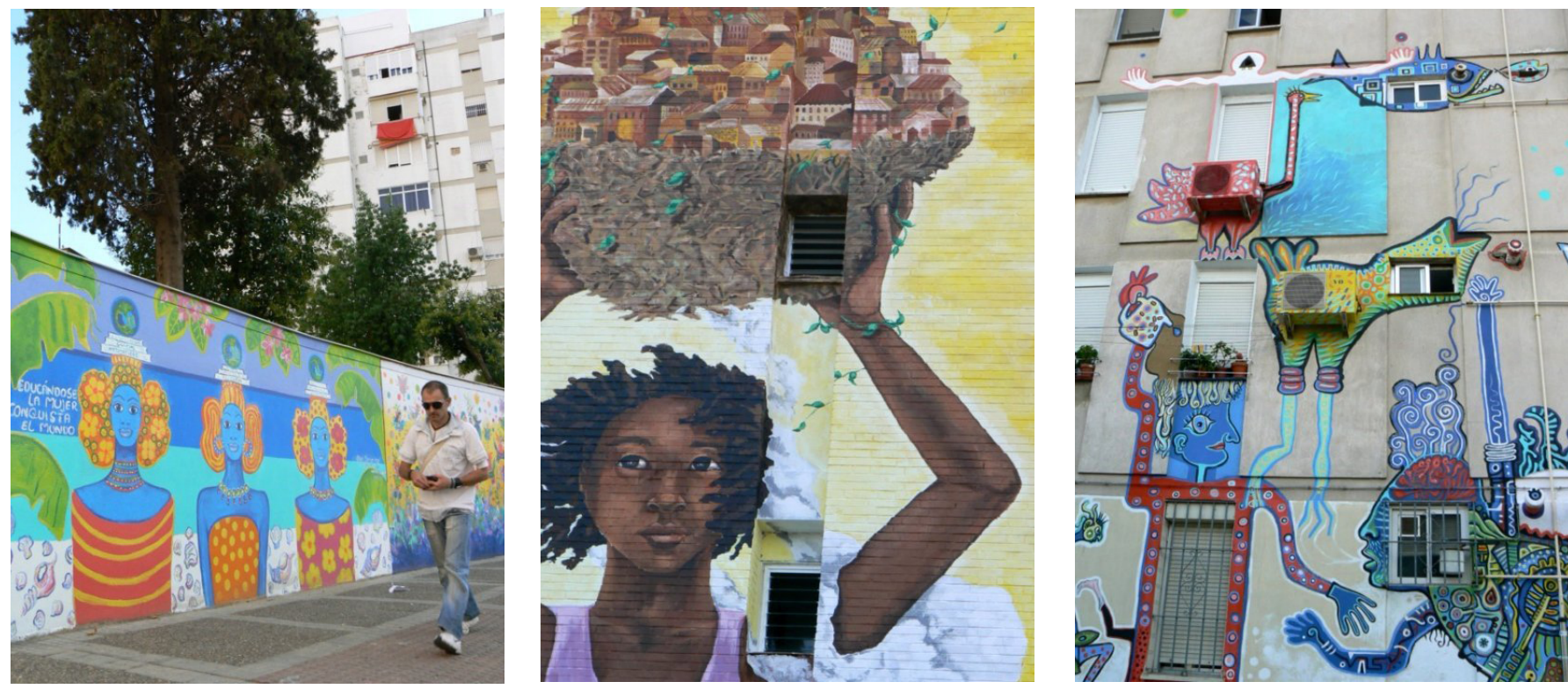

Arte para todos fue un proyecto artístico internacional que implicó activamente a los vecinos del Polígono de San Pablo (Sevilla)

servación preventiva, podrían aportar un mayor abanico de soluciones. Por ello, creemos que la dinamización e interpretación del patrimonio son una herramienta indispensable para la conservación de estos murales sin caer en el peligroso fenómeno de la fosilización. El arte urbano siempre ha sido un arte vivo, un arte provocativo, comunicador. No solo debemos proteger su integridad física si queremos de verdad conservarlo en su esencia.

\section{BIBLIOGRAFÍA}

- Estévez, L. (2010) El Polígono de San Pablo se convertirá en escenario del arte urbano. Diario de Sevilla, 26 de julio de 2010. Disponible en: https://www.diariodesevilla.es/ocio/ Poligono-San- Pablo-convertira-escenario_0_390561005.html [Consulta: 05/12/2020]

- Fernández Arcos, A. (2019) Propuesta de plan de conservación preventiva para proyectos de muralismo urbano. El caso de Vigo, ciudad de color. Ge-conservación, n. ${ }^{0} 16$, pp. 81-91 Disponible en: https://www.ge-iic.com/ojs/index.php/ revista/article/view/688 [Consulta: 12/04/2021]

- García, V. (2010) Un barrio convertido en galería de arte. Diario de Sevilla, 7 de octubre de 2010. Disponible en: https:// www.diariodesevilla.es/sevilla/barrio-convertido-galeriaarte_0_412459543.html [Consulta: 16/12/2020]
- Laboratorio Q (2021) Sevilla arte para todos. Disponible en: http://www.laboratorioq.com/global/laboratorioqsevilla/sevillaarte-para-todos/ [Consulta: 15/12/2021]

- Naciones Unidas (2010) Objetivos de Desarrollo del Milenio. ONU, Departamento de Asuntos Económicos y Sociales Disponible en: https://www.un.org/development/desa/es/ millennium-development-goals.html [Consulta: 20/01/2021]

- Piñero, F. (2014) San Pablo-Santa Justa, distrito del arte urbano de Sevilla. Sevilla Ciudad por $A B C$ de Sevilla, 29 de mayo de 2014. Disponible en: http://sevillaciudad.sevilla.abc. es/reportajes/s-pablo-sta-justa/cultura-s-pablo-sta-justa/arteurbano-experimento/ [Consuta: 16/01/2021]

- Sánchez Pons, M. (2016) Acercamiento a la evolución histórica y tecnológica de los materiales empleados en el grafiti y arte urbano. Ge-conservación, n. ${ }^{0} 10$, pp. 146-159. Disponible en: https://www.ge-iic.com/ojs/index.php/revista/ article/view/408 [Consulta: 12/04/2021]

- Schacter, R. (2016) Street Art Is a Period. Period. Or the Emergence of Intermural Art. Hyperallergic. Disponible en: https://hyperallergic.com/310616/street-art-is-a-period- periodor-the-emergence-of-intermural-art/ [Consulta: 09/02/2021] 